\title{
Chromosomal polymorphism in Drosophila willistoni populations from Uruguay
}

\author{
Vera Lúcia da Silva Valente ${ }^{1}$, Beatriz Goñi ${ }^{2}$, Victor Hugo Valiati ${ }^{1,3}$, Cláudia Rohde ${ }^{1}$ \\ and Nena Basílio Morales ${ }^{1}$ \\ ${ }^{1}$ Departamento de Genética, Instituto de Biociências, Universidade Federal do Rio Grande do Sul, \\ Porto Alegre, RS, Brazil. \\ ${ }^{2}$ Sección Genética Evolutiva, Instituto de Biología, Facultad de Ciencias, Universidad de la República, \\ Montevideo, Uruguay. \\ ${ }^{3}$ Laboratório de Biologia Molecular, Centro de Ciências da Saúde, Universidade do Vale \\ do Rio dos Sinos São Leopoldo, RS, Brazil.
}

\begin{abstract}
Chromosomal polymorphism in natural populations of Drosophila willistoni from Uruguay and southern Brazil was investigated in order to understand the genetic characteristics and evolutionary potential of these almost geographically marginal populations. The level of chromosomal polymorphism in samples from Uruguay was higher than in those from the southernmost Brazilian state of Rio Grande do Sul. The increase in the polymorphism of these populations, in which the species almost reaches its southern limit, contradicts the low level of paracentric inversion polymorphism expected under the central-marginal chromosomal polymorphism cline previously reported. The high frequency of some inversions and the presence of unique inversions in samples from Uruguay indicate the uniqueness of these populations.
\end{abstract}

Key words: Drosophila willistoni, chromosome inversion polymorphism, Uruguayan natural populations.

Received: June 12, 2002; accepted: November 8, 2002.

\section{Introduction}

Studies of the genetic characteristics of marginal populations make impossible to test the idea that gene flow is a cohesive force that holds a species together and allows it to evolve as a unit. Such populations may yield information on the role of heterozygosity at the chromosomal level, as in the case of many Drosophila species. A group of six species, including several subspecies and semispecies, closely resembling Drosophila willistoni, was discovered in Central and South America by Dobzhansky and his students, and intensively studied from 1943 to 1975 (reviewed by Cordeiro and Winge, 1995). Among its siblings, $D$. willistoni is the most widely distributed species, occurring from Florida in North America (Townsend, 1952), through the Bahamas, Central America and the Caribbean Islands (Dobzhansky, 1957), to the parallel 40, $300 \mathrm{~km}$ south of Buenos Aires, Argentina (Ehrman and Powell, 1982). Despite its status as a wild species, D. willistoni has been found in several man-altered environments (Townsend,

Send correspondence to Vera Lúcia da Silva Valente. E-mail: vera.gaiesky@ufrgs.br.
1958; Dobzhansky, 1965), in association with various widespread species (Parsons and Stanley, 1981) such as $D$. melanogaster, D. simulans, D. kikkawai, D. subobscura, D. hydei, D. immigrans, D. virilis and D. busckii (Valente and Araújo, 1986a; Goñi et al., 1998).

Chromosomal inversion in $D$. willistoni has served as a model for studying intrapopulation genetic variation and chromosomal polymorphism (Cordeiro and Dobzhansky, 1954; Da Cunha et al.,1959; Da Cunha and Dobzhansky, 1950, 1954; Dobzhansky, 1957; Pavan et al., 1957). Da Cunha and Dobzhansky (1954) recorded 50 inversions in D. willistoni samples collected at 78 localities stretching from southern Florida and central Mexico to the La Plata river and eastern foothills of the Andes near Tucuman, Argentina. Most of these inversions were widely distributed, although some were restricted to part of the species' range, while others were rare and endemic. More important were the significant geographic variations in the mean number of heterozygous inversions per individual. The highest frequency of inversion heterozygosis occurred in the central area of the species' geographic distribution, extending from western Bahia throughout central Brazil and most of the 
Amazon Basin to the eastern slopes of the Andes in Peru and Colombia, and the northeastern corner of the continent. The frequency of heterozygosis in this area declines toward the southern and northern limits of distribution in southern Brazil, Uruguay and Argentina, and in Central America and West Indies, especially in the Lesser Antilles. A further sharp decrease was observed in northeastern Brazil, a region of deserts and other sub-marginal habitats.

To explain the spectacular variation in chromosomal polymorphism observed in $D$. willistoni, Da Cunha et al. (1959) used the Ludwig's (1950) hypothesis which predicts a correlation between niche-with and genetic variability.Thus, populations that exploit a greater variety of ecological niches are expected to be more polymorphic than populations restricted to a narrow range of ecological opportunities. Based on some of their data, Da Cunha and Dobzhansky (1954) and Cunha et al. (1959) showed a positive correlation between environmental complexity and inversion heterozygosity at each locality and predicted the extent of chromosomal polymorphism expected in populations known to possess "certain climatic and biotic characteristics".

More recently, ecological, behavioral, and genetic studies on the evolutionary genetics of sibling species of the willistoni species subgroup inhabiting Rio Grande do Sul, southern Brazil, have been done by Valente and coworkers (Regner and Valente, 1993; Valente and Araujo, 1986a, 1986b; Valente and Morales, 1985; Valente et al., 1993; Valiati and Valente, 1996, 1997; Saavedra et al., 2001). Studies of chromosome inversion polymorphism in D. willistoni populations under high levels of environmental stress, such as those inhabiting the city of Porto Alegre, have identified a gradient of heterozygosis for inversions (Valente et al., 1993) and mating activity (Regner and Valente, 1993), related to the extent of environmental disturbance. The loss of chromosomal variability imposed by urbanization was interpreted as the action of selective forces in favor of structural homozygotes. A gradual adjustment of $D$. willistoni to the urban environment, seen as an increase in the heterozygosity of six polymorphic isoenzyme systems over the time has also been reported (Saavedra et al., 2001).

Reports of $D$. willistoni from several localities in Uruguay (Goñi et al., 1997, 1998), where the populations are considered to be almost geographically marginal, led us to investigate their gene arrangements. There is only one record of chromosomal inversion polymorphism for $D$. willistoni in this area (from Melo city, northeastern Uruguay), as reported by Da Cunha and Dobzhansky (1954). In the present paper, we describe chromosomal inversion polymorphisms among $D$. willistoni populations from Uruguay. The data are compared with the corresponding findings for populations from Rio Grande do Sul, the southernmost state in Brazil (Valente et al., 1993) which shares geographical borders with Uruguay.

\section{Materials and_Methods}

\section{Samples}

Samples from natural populations of $D$. willistoni were collected at nine sites in Uruguay (Figure 1) between 1991 and 1995. Table 1 shows the main environmental features, dates of collection and types of resources at each locality. Flies were collected in conventional banana baited traps and/or after emergency of adults reared on rotten fruit of native and exotic plants trsansported to the laboratory and stored at room temperature (as in Goñi et al., 1997, 1998). Isofemale lines were established after females collected in the field or emerged from fruit were cultured and the male offspring analyzed.

\section{Cytology}

Soon after establishing the isofemale lines, third instar larval offspring were dissected in Ephrussi and Beadle (1936) solution and processed for the analysis of polytene chromosomes, according to Ashburner (1967). Data on inversion polymorphisms for samples collected in 1986 and 1987 in and around the city of Porto Alegre $\left(51^{\circ} 06^{\prime} \mathrm{S} ; 30^{\circ} 10^{\prime} \mathrm{W}\right)$ and from around Eldorado do Sul $\left(30^{\circ} 05^{\prime} \mathrm{S} ; 51^{\circ} 30^{\prime} \mathrm{W}\right)$, both in the State of Rio Grande do Sul (RS), were used here. These data included unpublished

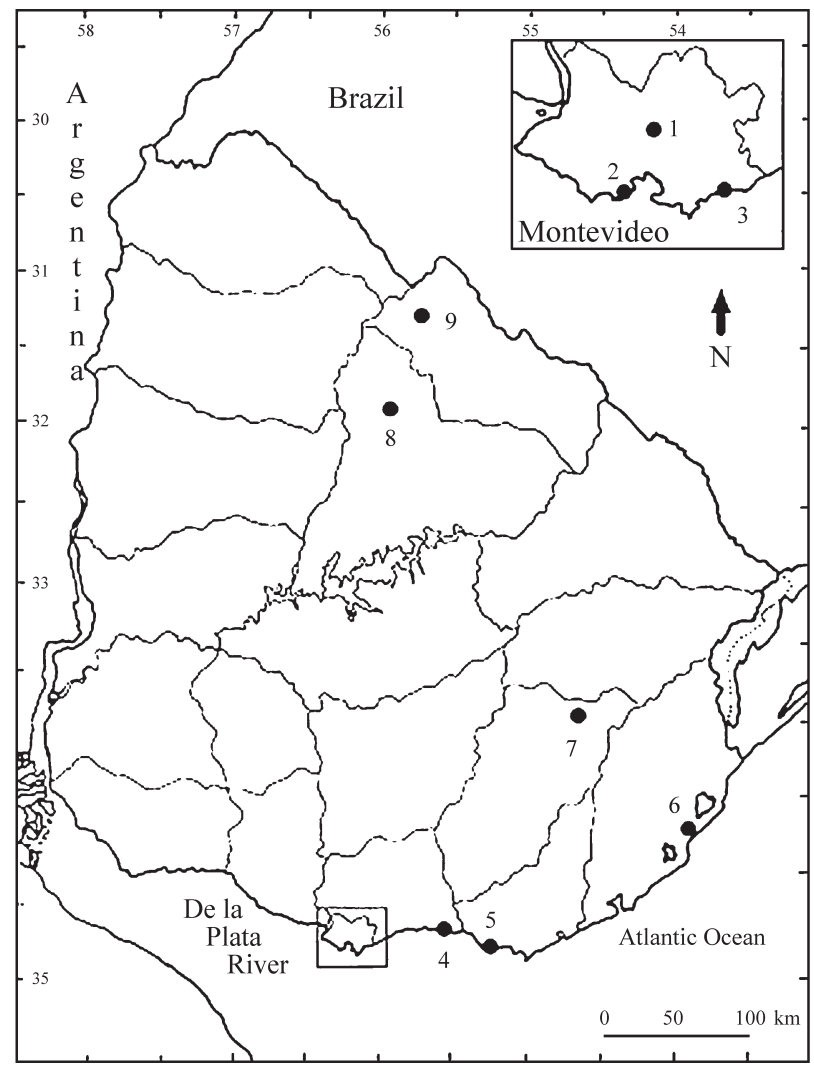

Figure 1 - Drosophila willistoni collection sites in Uruguay. The Montevideo district is shown in detail. Numbers refer to the collection sites indicated in Table 1. 
Table 1 - Sampled populations of Drosophila willistoni from Uruguay (see also Goñi et al., 1997 and 1998).

\begin{tabular}{|c|c|c|c|c|c|c|}
\hline \multirow[t]{2}{*}{ Locality $^{\mathrm{a}}$ (as Figure 1) } & \multirow[t]{2}{*}{ Environment } & \multirow[t]{2}{*}{ Samples ${ }^{\mathrm{b}}$} & \multirow[t]{2}{*}{ Month/year } & \multirow[t]{2}{*}{ Resources $^{\mathrm{c}}$} & \multicolumn{2}{|c|}{ D. willistoni } \\
\hline & & & & & $\mathrm{N}$ & $\%$ \\
\hline \multirow[t]{5}{*}{ 1. Facultad de Agronomía, Montevideo } & \multirow[t]{5}{*}{ Urban } & \multirow[t]{2}{*}{$1 \mathrm{U}$} & May/91 & S. romanzoffiana $(\mathrm{N})$ & 398 & 9.5 \\
\hline & & & June/91 & G. biloba $(\mathrm{E})$ & 391 & 2.8 \\
\hline & & \multirow[t]{3}{*}{$2 \mathrm{U}$} & April/95 & G. biloba $(\mathrm{E})$ & 482 & 12.4 \\
\hline & & & April/95 & D. caffra $(\mathrm{E})$ & 16 & 31.2 \\
\hline & & & April/95 & S. romanzoffiana $(\mathrm{N})$ & 810 & 4.7 \\
\hline \multirow[t]{2}{*}{ 2. Parque Vaz-Ferreira, Montevideo } & Urban, mixed forest (pound) & \multirow[t]{2}{*}{$3 \mathrm{U}$} & June/94 & Banana bait & 65 & 7.7 \\
\hline & Idem (golf field) & & June/94 & Banana bait & 208 & 5.3 \\
\hline 3. Plaza Fabini, Montevideo & Urban & $4 \mathrm{U}$ & April/95 & S. romanzoffiana $(\mathrm{N})$ & 204 & 2.9 \\
\hline 4. Santa Lucía del Este, Canelones & De la Plata River coast, urban & $5 \mathrm{U}$ & April/94 & B. capitata $(\mathrm{N})$ & N.D. & N.D. \\
\hline 5. Cerro del Toro, Maldonado & De la Plata River coast, natural & $6 \mathrm{U}$ & Feb./94 & Banana bait & 16 & 6.3 \\
\hline 6. Boca del Sarandí, Rocha & Atlantic wetland, natural & $7 \mathrm{U}$ & April/95 & Banana bait & N.D. & N.D. \\
\hline 7. Sauce del Cebollatí, Lavalleja & Natural praire & $8 \mathrm{U}$ & April/95 & B. capitata $(\mathrm{N})$ & 205 & 32.7 \\
\hline 8. Tacuarembó, Tacuarembó & Urban & $9 \mathrm{U}$ & March/95 & B. capitata $(\mathrm{N})$ & 314 & 2.6 \\
\hline 9. Arroyo Gajo del Lunarejo, Riveira & Upriver, natural & $10 \mathrm{U}$ & June/95 & C. sinensis $(\mathrm{E})$ & 4 & 100 \\
\hline
\end{tabular}

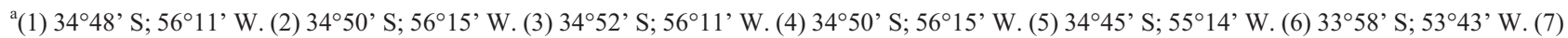

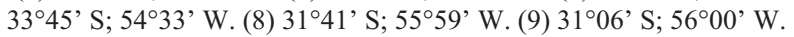

${ }^{\mathrm{b}}$ As in Table 2 and Figures 2, 3, 4.

${ }^{\mathrm{c}}$ Flies were emerged and/or collected from: Butia capitata (fr.), Citrus sinensis (fr.), Doryalis caffra (fr.), Gingko biloba (fr) and Syagrus romanzoffiana (fr).

$\mathrm{N}=$ Native (Neotropical), $\mathrm{E}=$ Exotic (cultivated). N.D. = Non determined.

findings on $\mathrm{X}$ chromosome inversions and results for chromosomes 2 and 3 reported by Valente et al. (1993) and shown in Appendix 1. The chromosomal inversions, detected as heterozygotes, were registered, photomicrographed and compared with the figures and descriptions of polytene chromosomes recorded by Dobzhansky (1950, 1957), Da Cunha and Dobzhansky (1954), Da Cunha et al. (1950, 1959), Regner et al. (1996). They were also compared with inversions recorded by Valente and Morales (1985) and with unpublished records of Dr A.R. Cordeiro available in our Department at UFRGS. Only heterozygous inversions were detected in D. willistoni.

\section{Statistical procedures}

The exact permutational test described by Roff and Bentzer (1989) was used to compare the degree of heterozygosis between and within population samples from Uruguay and RS. This test is useful when the expected values are very small, as is the Uruguayan samples. The numbers of total heterozygotes versus total homozygotes for each inversion, were compared using the adjusted residuals test (Everitt, 1992). When the later test gave a significant $\chi^{2}$ value, each cell of the table of comparisons was analyzed individually and compared with the critical values of a normal distribution (e.g., $\mathrm{Z}_{0.05}=1.96$ ). Positive or negative signs indicated an excess or reduction in each category relative to the expected value, as calculated using a contingency table. The inversion frequencies were used to assess the similarities between the populations through cluster analysis. The Manhattan distance was used as a dissimilarity coefficient for the UPGMA (unweighted pair-group method using arithmetic averages) cluster algorithm (Sneath and Sokal, 1973).

\section{Results}

Table 1 shows the characteristics of the Uruguayan populations of $D$. willistoni. Three populations, localities 1 to 3, were located in urban or suburban areas of Montevideo (Figure 1). In general, the percentage of D. willistoni in each sample was low, and may reflect the scarcity of the species at these localities.

Table 2 shows the frequencies of inversion heterozygotes and the estimates of chromosomal polymorphism in populations from Uruguay. In general, these populations were highly polymorphic, with a wide range in the mean number of heterozygous inversions per female (1.47-3.17). Twenty-three types of inversions were segregated, with IIL and III being the most polymorphic chromosomal arms. There were 2-7 types of inversions in IIL and 2-5 types of inversions in III. Two known widespread inversions, IIR E and III $\mathrm{H}$, were absent in our samples (Table 2), but were previously recorded in a single larva from Melo, Uruguay (32²0' S; 54 $07^{\circ}$ W) (Da Cunha and Dobzhansky, 1954).

Table 3 summarizes the frequencies of inversions and the estimates of chromosomal polymorphism for the $\mathrm{X}$ chromosome in the RS populations. The frequency of chromosomal polymorphism in both arms of the $\mathrm{X}$ chromosome 
Table 2 - Frequency (\%) of inversions, total heterozygosis, and mean number of inversions per chromosome and per female of Drosophila willistoni populations from Uruguay. Percentages above 100 after summation indicate more than one inversion per chromosomal arm.

\begin{tabular}{|c|c|c|c|c|c|c|c|c|c|c|c|}
\hline \multirow[b]{2}{*}{ Chrom. } & \multirow[b]{2}{*}{ Invs. } & \multicolumn{10}{|c|}{ Samples ${ }^{\mathrm{a}}$} \\
\hline & & $1 \mathrm{U}$ & $2 \mathrm{U}$ & $3 \mathrm{U}$ & $4 \mathrm{U}$ & $5 \mathrm{U}$ & $6 \mathrm{U}$ & $7 \mathrm{U}$ & $8 \mathrm{U}$ & $9 \mathrm{U}$ & $10 \mathrm{U}$ \\
\hline \multirow[t]{2}{*}{$\mathrm{XL}$} & POA3 & 2.3 & - & 5.5 & - & 8.3 & 16.7 & 6.3 & 14.7 & - & - \\
\hline & A & - & - & - & - & 8.3 & - & - & - & - & - \\
\hline Total Het. (\%) & & 2.3 & - & 5.5 & - & 16.6 & 16.7 & 6.3 & 14.7 & - & - \\
\hline Flies analyzed & & 43 & 92 & 18 & 30 & 12 & 12 & 16 & 61 & 23 & 17 \\
\hline X Invs./ chrom. & & 0.023 & - & 0.056 & - & 0.167 & 0.167 & 0.062 & 0.147 & - & - \\
\hline Invs. Types & & 1 & - & 1 & - & 2 & 1 & 1 & 1 & - & - \\
\hline \multirow[t]{2}{*}{$\mathrm{XR}$} & $\mathrm{E}$ & - & - & - & - & - & - & - & 8.2 & - & - \\
\hline & B1 & - & 1.1 & - & - & 8.3 & 8.3 & - & 1.6 & - & - \\
\hline Total Het. (\%) & & - & 1.1 & - & - & 8.3 & 8.3 & - & 9.8 & - & - \\
\hline Flies analyzed & & 43 & 92 & 18 & 30 & 12 & 12 & 16 & 61 & 23 & 17 \\
\hline X Invs./ chrom. & & - & 0.011 & - & - & 0.083 & 0.083 & - & 0.098 & - & - \\
\hline Invs. Types & & - & 1 & - & - & 1 & 1 & - & 2 & - & - \\
\hline \multicolumn{2}{|c|}{ Invs. Types (XL + XR) } & 1 & 1 & 1 & - & 3 & 2 & 1 & 3 & - & - \\
\hline \multirow[t]{8}{*}{ IIL } & $\mathrm{D}$ & 30.2 & 9.8 & 22.2 & - & - & - & - & 16.4 & 13.4 & - \\
\hline & $\mathrm{E}$ & 53.5 & 53.3 & 61.1 & 70.0 & 83.3 & 83.3 & - & 34.3 & 34.8 & 11.8 \\
\hline & $\mathrm{F}$ & 25.6 & 6.5 & 50.0 & 30.0 & 33.3 & 33.3 & 50.0 & 39.3 & 52.2 & 35.3 \\
\hline & $\mathrm{H}$ & 4.6 & 19.6 & - & 30.0 & - & - & 6.3 & 24.6 & - & - \\
\hline & $\mathrm{B}$ & 25.6 & 18.5 & 61.1 & 36.6 & - & - & 43.7 & 9.8 & - & - \\
\hline & A & - & 3.3 & 11.1 & 20.0 & 8.3 & 8.3 & - & 3.3 & - & - \\
\hline & I & - & 5.4 & - & - & 8.3 & 8.3 & 18.7 & 11.5 & 17.4 & - \\
\hline & desc. & - & - & - & - & - & - & - & - & 4.3 & - \\
\hline Total Het. (\%) & & 74.4 & 76.1 & 94.4 & 100.0 & 100.0 & 100.0 & 68.7 & 91.8 & 91.3 & 47.1 \\
\hline Flies analyzed & & 43 & 92 & 18 & 30 & 12 & 12 & 16 & 61 & 23 & 17 \\
\hline X Invs./ chrom. & & 1.395 & 1.187 & 2.055 & 1.866 & 1.333 & 1.333 & 1.187 & 1.393 & 1.217 & 0.471 \\
\hline Invs. Types & & 5 & 7 & 5 & 5 & 4 & 4 & 4 & 7 & 5 & 2 \\
\hline \multirow[t]{4}{*}{ IIR } & $\mathrm{C}$ & 19.0 & - & 11.1 & - & 8.3 & 8.3 & - & - & - & - \\
\hline & B & - & - & 11.1 & - & - & - & - & - & - & - \\
\hline & G & - & - & 11.1 & - & - & - & - & - & - & - \\
\hline & desc. & 2.4 & 1.1 & - & - & - & - & - & 1.6 & - & - \\
\hline Total Het. (\%) & & 21.4 & 1.1 & 33.3 & - & 8.3 & 8.3 & - & 1.6 & - & - \\
\hline Flies analyzed & & 42 & 92 & 18 & 30 & 12 & 12 & 16 & 61 & 23 & 17 \\
\hline X Invs./ chrom. & & 0.214 & 0.011 & 0.333 & - & 0.083 & 0.083 & - & 0.016 & - & - \\
\hline Invs. Types & & 2 & 1 & 3 & - & 1 & 1 & - & 1 & - & - \\
\hline \multicolumn{2}{|l|}{ Invs. Types $(2 \mathrm{~L}+2 \mathrm{R})$} & 7 & 8 & 8 & 5 & 5 & 5 & 4 & 8 & 5 & 2 \\
\hline \multirow[t]{6}{*}{ III } & $\mathrm{J}$ & 39.5 & 48.9 & 22.2 & 23.3 & 50.0 & 50.0 & 68.7 & 65.0 & 43.5 & - \\
\hline & B & 32.5 & 20.6 & 0.5 & 33.3 & 58.0 & 58.0 & 43.7 & 3.3 & 60.9 & - \\
\hline & $\mathrm{C}$ & 9.3 & 51.1 & 5.5 & 16.7 & - & - & - & 26.6 & 17.4 & 88.2 \\
\hline & V1 & 11.6 & - & - & - & - & - & - & 1.7 & - & 11.8 \\
\hline & $\mathrm{N}$ & 2.3 & - & - & - & - & - & - & - & - & - \\
\hline & M & - & - & - & - & - & - & - & 1.7 & - & - \\
\hline Total Het. (\%) & & 72.1 & 79.3 & 72.2 & 60.0 & 91.7 & 91.7 & 87.5 & 80.0 & 86.9 & 88.2 \\
\hline Flies analyzed & & 43 & 92 & 18 & 30 & 12 & 12 & 16 & 60 & 23 & 17 \\
\hline X Invs./ chrom. & & 0.953 & 1.206 & 0.778 & 0.733 & 1.083 & 1.083 & 1.125 & 0.983 & 1.218 & 1.000 \\
\hline Invs. Types & & 5 & 3 & 3 & 3 & 2 & 2 & 2 & 5 & 3 & 2 \\
\hline \multicolumn{12}{|l|}{ All chromosomal arm } \\
\hline $\mathrm{X} /$ Invs./female & & 2.59 & 2.39 & 3.17 & 2.60 & 2.75 & 2.75 & 2.37 & 2.63 & 2.43 & 1.47 \\
\hline Invs. Types/samples & & 13 & 12 & 12 & 8 & 10 & 9 & 7 & 16 & 8 & 4 \\
\hline
\end{tabular}

${ }^{\text {a }}$ As in Table 1. 
Table 3 - Frequency (\%) of inversions, total heterozygosis, and mean number of inversions per each arm of the X chromosome of Drosophila willistoni populations from Rio Grande do Sul.

\begin{tabular}{|c|c|c|c|c|c|c|c|c|c|c|c|}
\hline & \multirow[b]{2}{*}{ Chrom. } & \multirow[b]{2}{*}{ Invs. } & \multicolumn{9}{|c|}{ Samples ${ }^{a}$} \\
\hline & & & 1B & $2 \mathrm{~B}$ & $3 \mathrm{~B}$ & $4 \mathrm{~B}$ & $5 \mathrm{~B}$ & $6 \mathrm{~B}$ & $7 \mathrm{~B}$ & $8 \mathrm{~B}$ & $9 \mathrm{~B}$ \\
\hline & \multirow[t]{5}{*}{$\mathrm{XL}$} & A & - & - & - & - & 0.3 & - & - & - & - \\
\hline & & $*$ & 0.3 & - & - & - & - & - & - & - & - \\
\hline & & $\mathrm{D}$ & - & - & 0.5 & - & - & - & 1.1 & - & - \\
\hline & & I & - & - & - & - & - & - & - & - & - \\
\hline & & $\mathrm{H}$ & - & - & - & - & - & - & 1.1 & - & - \\
\hline Total Het. (\%) & & & 0.30 & - & 0.50 & - & 0.32 & - & 2.22 & - & - \\
\hline Flies analyzed & & & 355 & 186 & 201 & 114 & 315 & 232 & 540 & 231 & 288 \\
\hline $\bar{X}$ Invs./ chrom. & & & 0.003 & - & 0.005 & - & 0.003 & - & 0.022 & - & - \\
\hline \multirow[t]{6}{*}{ Invs. Types } & & & 1 & - & 1 & - & 1 & - & 2 & - & - \\
\hline & \multirow[t]{5}{*}{ XR } & $\mathrm{E}$ & 0.3 & 0.5 & - & - & 1.3 & 0.4 & 0.5 & - & - \\
\hline & & B & - & - & - & - & - & - & - & - & - \\
\hline & & $\mathrm{F}$ & - & - & - & - & - & - & - & - & - \\
\hline & & $\mathrm{C}$ & - & - & - & - & - & - & 0.5 & - & - \\
\hline & & A & - & - & - & - & - & - & - & - & - \\
\hline Total Het. (\%) & & & 0.30 & 0.54 & - & - & 1.30 & 0.40 & 1.11 & - & - \\
\hline Flies analyzed & & & 355 & 185 & 201 & 114 & 315 & 232 & 540 & 231 & 288 \\
\hline X Invs./ chrom. & & & 0.003 & 0.005 & - & - & 0.013 & 0.004 & 0.011 & - & - \\
\hline Invs. Types & & & 1 & 1 & - & - & 1 & 1 & 2 & - & - \\
\hline Invs. Types (XL & + XR) & & 2 & 1 & 1 & - & 2 & 1 & 4 & - & - \\
\hline
\end{tabular}

Table 3 (cont.)

\begin{tabular}{|c|c|c|c|c|c|c|c|c|c|c|c|c|}
\hline & \multirow[b]{2}{*}{ Chrom. } & \multirow[b]{2}{*}{ Invs. } & \multicolumn{10}{|c|}{ Samples $^{\mathrm{a}}$} \\
\hline & & & $10 \mathrm{~B}$ & $11 \mathrm{~B}$ & $12 \mathrm{~B}$ & $13 \mathrm{~B}$ & 14B & $15 \mathrm{~B}$ & $16 \mathrm{~B}$ & 17B & $18 \mathrm{~B}$ & 19B \\
\hline & \multirow[t]{5}{*}{$\mathrm{XL}$} & A & - & - & - & - & - & 1.0 & - & - & - & - \\
\hline & & * & - & - & - & 0.8 & - & 0.8 & - & - & - & - \\
\hline & & $\mathrm{D}$ & 0.4 & - & - & - & - & 0.6 & - & 4.2 & - & - \\
\hline & & I & - & - & - & - & - & - & - & 1.0 & - & - \\
\hline & & $\mathrm{H}$ & - & - & - & - & - & - & - & - & - & - \\
\hline Total Het. (\%) & & & 0.36 & - & - & 0.80 & - & 2.50 & - & 5.26 & - & - \\
\hline Flies analyzed & & & 558 & 383 & 41 & 130 & 192 & 480 & 213 & 95 & 330 & 407 \\
\hline$\overline{\mathrm{X}}$ Invs./ chrom. & & & 0.004 & - & - & 0.008 & - & 0.025 & - & 0.053 & - & - \\
\hline \multirow[t]{6}{*}{ Invs. Types } & & & 1 & - & - & 1 & - & 3 & - & 2 & - & - \\
\hline & \multirow[t]{5}{*}{ XR } & E & 0.5 & - & - & - & - & 0.4 & - & - & - & 0.2 \\
\hline & & B & - & 0.5 & - & - & - & - & 2.3 & - & - & - \\
\hline & & $\mathrm{F}$ & - & - & - & - & 0.5 & - & - & - & - & - \\
\hline & & $\mathrm{C}$ & - & 0.8 & - & - & - & - & - & - & - & 0.2 \\
\hline & & A & 0.7 & 1.0 & - & - & - & - & - & - & - & - \\
\hline Total Het. $(\%)$ & & & 1.25 & 2.35 & - & - & 0.52 & 0.42 & 2.35 & - & - & 0.50 \\
\hline Flies analyzed & & & 558 & 383 & 41 & 130 & 193 & 480 & 213 & 94 & 330 & 407 \\
\hline X Invs./ chrom. & & & 0.013 & 0.023 & - & - & 0.005 & 0.004 & 0.023 & - & - & 0.005 \\
\hline Invs. Types & & & 2 & 3 & - & - & 1 & 1 & 1 & - & - & 2 \\
\hline Invs. Types (XI & + XR) & & 3 & 3 & - & 1 & 1 & 4 & 1 & 2 & - & 2 \\
\hline
\end{tabular}

*Corresponds to the basal (undescribed) inversion 1-2.

${ }^{\text {a }}$ Samples from 1 to 14 correspond to urban and sub-urban sites of Porto Alegre city; samples 15 and 16 correspond to Cascata hill and Pintada island respectively, natural neighboring places of Porto Alegre city $\left(30^{\circ} 2^{\prime} \mathrm{S} ; 51^{\circ} 14^{\prime} \mathrm{W}\right)$, and samples 17 to 19 correspond to non-urban places Eldorado county $\left(30^{\circ} 05^{\prime} \mathrm{S} ; 51^{\circ} 30^{\prime} \mathrm{W}\right), 40 \mathrm{~km}$ apart from Porto Alegre city. 
was low, only three inversions being detected in three samples. The mean number of inversions per female (chromosomes II, III and X together) in these populations ranged from 1.56 to 3.26 and segregated a total of 37 types of inversions, with IIL (3-8 types of inversions) and III (4-8 types of inversions) being the most polymorphic arms (see Valente et al., 1993 and Appendix 1).

The configurations of the heterozygous inversions found in the Uruguayan samples of $D$. willistoni were recently published in Valente et al. (2001). Most of them are also common in populations from Rio Grande do Sul Brazilian State (see Valente and Araújo, 1986; Valente et al., 1993 and Appendix 1).

There were no significant differences $(p>0.05)$ when the number of inversion types occurring in each chromosome arm was compared within and among all sampled populations (Uruguay and RS). Similar results were obtained when the distribution of the number of inversions for each chromosome arm was tested. However, the absolute number of different inversions in each chromosome arm within and among the sampled populations differed significantly $(\mathrm{p}<0.05)$ for all chromosome arms except the XR arm (heterogeneous within the samples from Uruguay).

Considering the proportion of structural variability, the total frequency $(\%)$ of inversion heterozygosis in the sampled populations (Tables 2 and 3 this paper, and Table 2 in Valente et al., 1993 or in Appendix 1) differed among chromosome arms. In all cases, the X chromosome (both $\mathrm{XL}$ and $\mathrm{XR}$ ) and the right arm of the second chromosome
(IIR) tended to be more homozygous, whereas the left arm of the second chromosome (IIL) and the third (III) chromosome showed the opposite tendency.

Table 4 shows the total number and frequency (\%) of inversion heterozygosis and homozygosis in each chromosome arm in the Uruguayan and RS populations. Comparison of the total heterozygosis versus the total homozygosis for each chromosome arm, the two populations showed that samples from Uruguay were more polymorphic (for the $\mathrm{XL}, \mathrm{XR}$, and IIL chromosome arms) than those from RS. The adjusted residual test showed that the differences were caused by an excess of inversion heterozygosity in the samples from Uruguay, i.e., $\mathrm{XL}(\mathrm{Z}=8.16), \mathrm{XR}(\mathrm{Z}=3.76)$ and IIL $(Z=5.18)$. The proportion of heterozygosis in the other chromosome arms (IIR and III), was similar in the populations sampled.

The dendrograms in Figures 2 to 4 (upper part) represent all of the sampled populations (29) of D. willistoni (as in Tables 2 and 3), grouped based on the similarity/dissimilarity in the inversion frequencies in each arm. The contribution of each inversion type to the respective chromosome cluster is shown in the lower part of Figures 2 to 4 .

Figure 2a shows the samples grouped according to the similarity-dissimilarity in the XL inversion frequencies. Samples $5 U, 6 U$, and $8 U$ from Uruguay were the most different and separated early from a cluster that grouped the other samples. As indicated in Figure 2b, which were clustered based on the contribution of the XL type inversions. The XL POA3 inversion, for instance, occurred exclusively

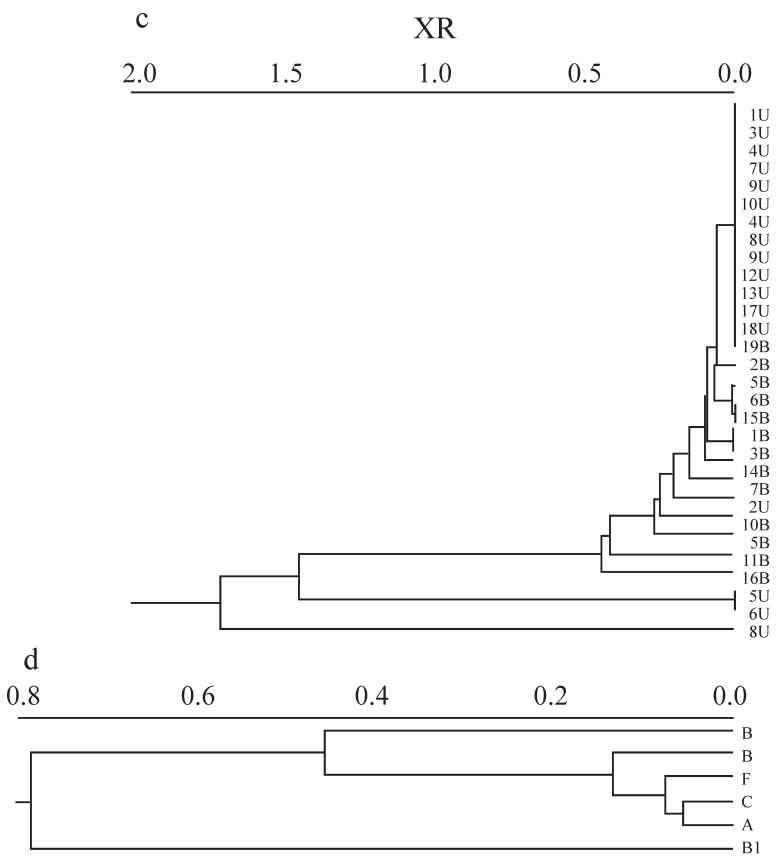

Figure 2 - Relationships among D. willistoni populations from Uruguay and Rio Grande do Sul based on the similarities/dissimilarities of the inversions on chromosome arms XL (a,b) and XR (c,d) using the UPGMA method. (a) Cluster based on the frequencies of heterozygous inversions in XL and (b) the contribution of each type of XL inversion to the clustering in (a). (c) and (d), as in (a) and (b) but for chromosome arm XR. Population samples as in Tables 2 and 3 . 
in populations from Uruguay (Tables 2 and 3 ) and generated the observed inversion dissimilarity, based on its occurrence (presence/absence) and frequencies. Four clusters involving samples from Uruguay were formed by the contribution of XL POA3, and a fifth cluster was formed through an XL A inversion (Figure 2a, Table 2). The first group formed by the $5 U$ (Santa Lucía) sample was the most different, and had only the XL A inversion. The second group, formed by samples $6 U$ (Cerro del Toro) and $8 U$ (Sauce del Cebollatí), showed the highest frequencies for the XL POA3 inversion. The third group, formed by samples $7 U$ (Boca del Sarandí) and $3 U$ (Parque Vaz-Ferreira), had intermediate frequencies for the XL POA 3 inversion, while the fourth group included sample the $1 U$ (Facultad de Agronomía) which had a low XL POA 3 inversion frequency $(2.33 \%)$. The other samples from Uruguay did not show this inversion and were clustered together.

All samples, except three from Uruguay $(5 U, 6 U$, and $8 U$ ), were roughly similar with respect to the inversions on $\mathrm{XR}$ (Figure 2c). When the contribution of the XR inversion types was considered (Figure 2d), the XR B1 inversion contributed the most, and was recorded only in four samples from Uruguay. On the other hand, the XR E inversion, quite common among RS populations, was only detected in sample $8 U$ (Sauce del Cebollatí) from Uruguay.The high frequency of the XR E inversion in this sample could have contributed to the observed cluster pattern (Figure 2c).

a

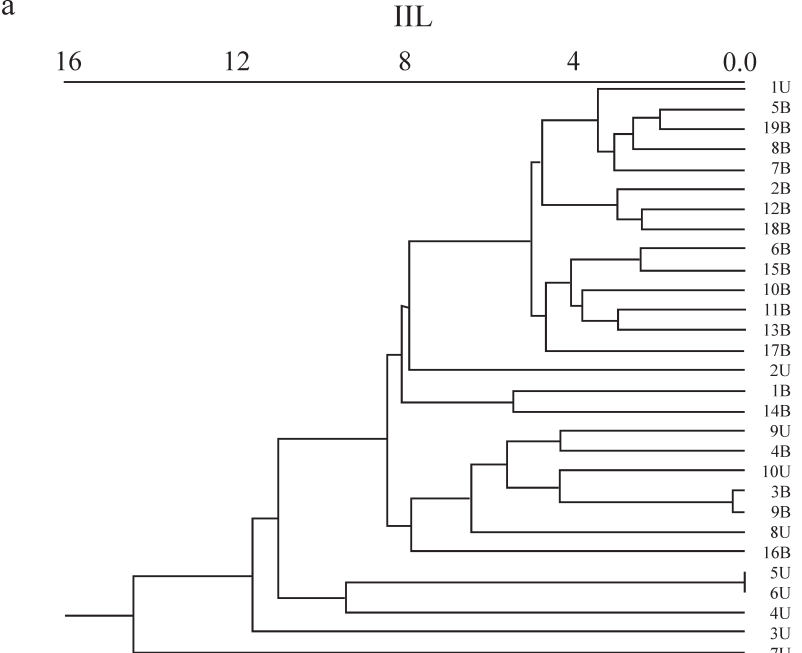

b

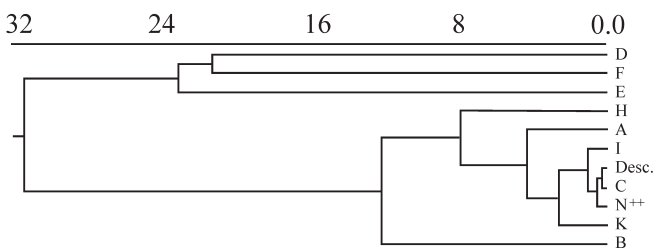

Figure 3a shows the population samples grouped according to the frequency of similarities-differences in IIL inversions. The result is a phenogram with several clusters. An unrooted sample from Uruguay, Boca del Sarandí (7U), differed from all other populations. The absence of the IIL E inversion in this population could have contributed to its earlier separation. The next two big clusters were formed by the IIL inversion frequency (Figure 3b). One was formed by the widespread inversions IIL D, F and E, and the other by the IIL B, H, A and I inversions, and the IIL C, $\mathrm{N}^{++}$and "Desc." endemic inversions.

The formation of the IIR inversion clusters (Figure 3c) cannot be explained sole by the absence of the inversion IIR E in samples from Uruguay (Figure 3d). Rather, the high frequencies for the IIR B and $\mathrm{G}$ inversions in the Parque Vaz-Ferreira $(3 U)$ sample (11\%, Table 2) may account for its early separation (Figure 3c). A subsequent cluster that insulated the Facultad de Agronomia (1U) sample, was probably caused by the presence and high frequency $(19 \%)$ of the IIR C inversion. The next group, formed by samples $5 U$ and $6 U$, apparently also resulted from IIR C inversions.

Finally, the third chromosome (III), characterized by the highest number of inversion types (15), resulted in the formation of two main clusters (Figure 4a); one included the Arroyo Gajo del Lunarejo (10U) sample and the other, all of the remaining samples. The uniqueness of the $(10 U)$

c

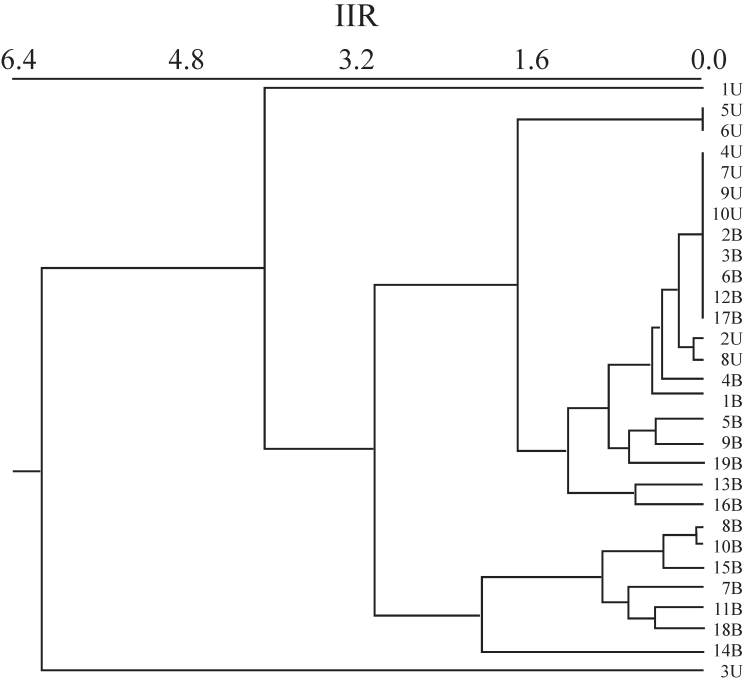

d

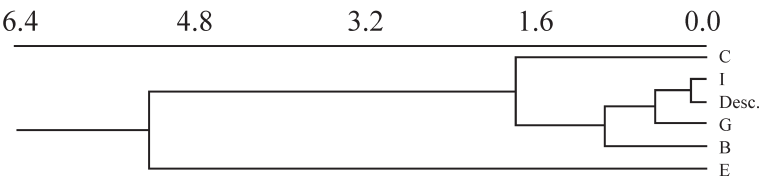

Figure 3 - Relationships among D. willistoni populations from Uruguay and Rio Grande do Sul based on the similarities/dissimilarities of the inversions on chromosome arms IIL (a,b) and IIR (c,d) using the UPGMA method. (a) Cluster based on the frequencies of heterozygous inversions in IIL and (b) the contribution of each type of IIL inversion to the clustering in (a). (c) and (d), as in (a) and (b) but for chromosome arm IIR. Population samples as in Table 2, but see also Valente et al. (1993) and Appendix 1. 


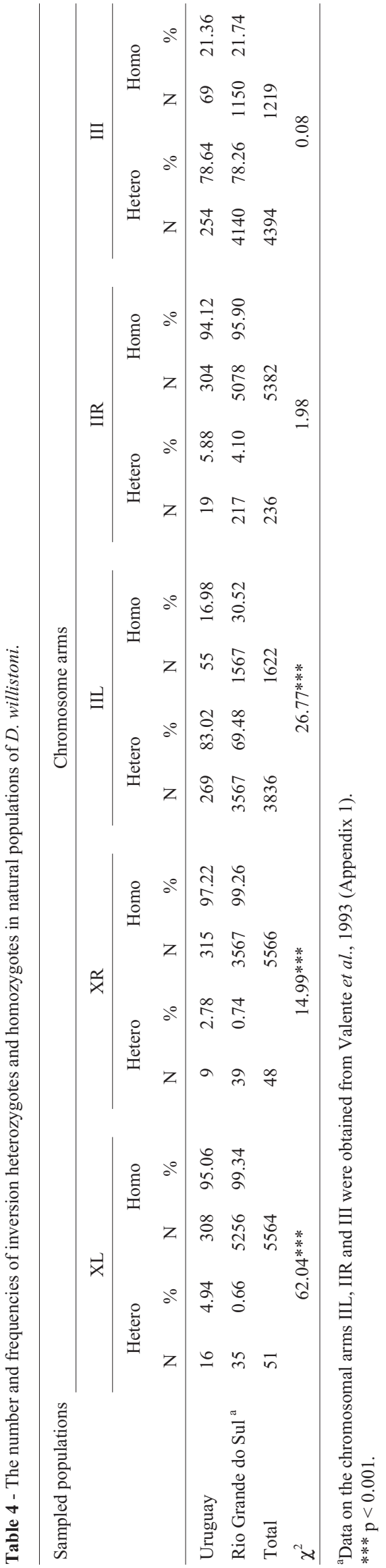

a

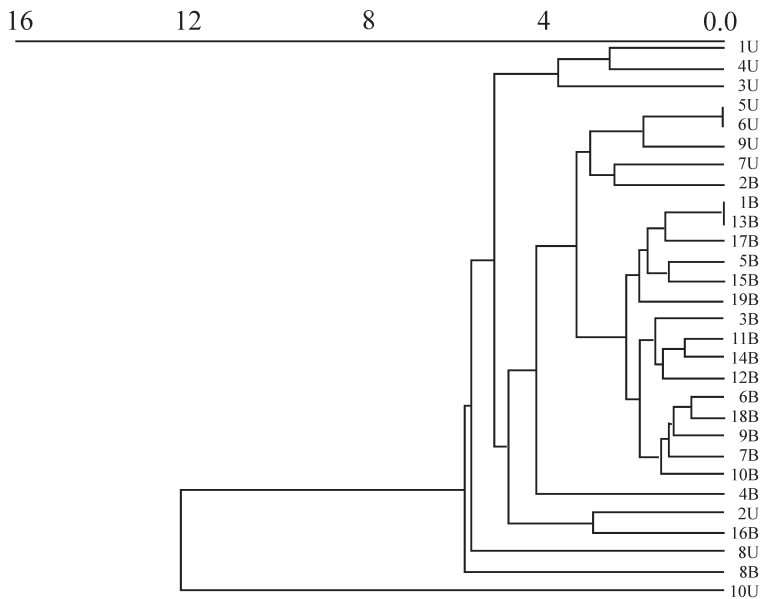

b

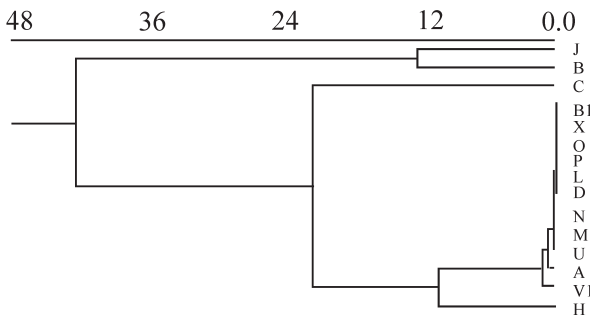

Figure 4 - Relationships among the $D$. willistoni populations from Uruguay based on similarities/dissimilarities of chromosome III inversions using the UPGMA method. (a) Cluster based on the frequencies of heterozygous inversions in chromosome III and (b) the contribution of each type of chromosome III inversion to the clustering in (a). Population samples as in Table 2, but see also Valente et al. (1993) and Appendix 1.

population resulted from the absence of the widespread III $\mathrm{J}$ and B inversions (Figure $4 \mathrm{~b}$ ); all of the other samples had similar frequencies and types of inversions (Table 2). The Arroyo Gajo del Lunarejo (10U) sample had the highest frequency $(88.2 \%)$ of III C inversions among all of the other samples and shared the III V1 inversion (at a high frequency of $11.8 \%$ ) with two other samples from Uruguay ( $1 U$ and $8 U$, Table 2). Other minor chromosome III clusters were formed: the $8 \mathrm{~B}$ sample from RS probably resulted from the high frequency of III $\mathrm{H}$ inversions commonly found in populations from this region (Valente and Araújo, 1986b; Valente et al., 1993).

Overall, different grouping patterns were detected among the populations sampled. In general, samples from Uruguay were more heterogeneous than those from RS. Highly represented inversions, such as the XR B1 and IIR C inversions in samples from Uruguay (see Table 2), and those barely detected, such as the endemic III $\mathrm{H}$ inversion in samples from urban Porto Alegre (Appendix 1), may have contributed to the observed patterns of clustering.

\section{Discussion}

Central-marginal or central-peripheral clines of paracentric inversion polymorphism have been observed in 
most chromosomally polymorphic species of Drosophila (reviewed by Soulé, 1973). The geographic distribution of chromosomal polymorphism in $D$. willistoni first elucidated by Da Cunha and Dobzhansky (1954), Da Cunha et al. (1959), Dobzhansky (1957), Dobzhansky et al. (1950) and Townsend (1958) showed that populations from the southern and northern limits of the species distribution were less polymorphic than centrally located populations. Our data showed that the $D$. willistoni populations sampled in Uruguay, were highly polymorphic, with a wide range of values for the mean number of inversions per female (1.47-3.17), and were more polymorphic (for chromosome arms XR, XL and IIL) than the neighboring populations from southern Brazil.

Our results agree with a previous report for a sample $(\mathrm{N}=67)$ from Uruguay which showed a mean frequency $(2.83 \pm 0.33)$ of inversions per female (Da Cunha and Dobzhansky, 1954). On the other hand, our data do not support the expected low level of chromosomal inversion heterozygosity in populations of $D$. willistoni located in areas located close to the limits of the species' distribution (Spassky et al., 1971). Rare chromosomal arrangements, such as the XR B1 inversion and the III N inversion, were detected in the samples from Uruguay. The III N inversion had been reported previously in a sample from Melo city (Da Cunha and Dobzhansky,1954). The inversion POA3 on $\mathrm{XL}$, quite a rare inversion in the RS populations (never found at latitudes lower than Porto Alegre $\left(30^{\circ} \mathrm{S}, 51^{\circ} \mathrm{W}\right.$, Regner et al., 1996), was, however, quite common among the samples from Uruguay. Selective forces may be responsible for eliminating variants such as IIR E and III H in Uruguayan populations but which are extremely common in RS samples. The adaptive value of chromosome inversion polymorphism in these almost marginal populations can only be determined after further ecological and populational studies. In addition, the small sample size of the populations examined here suggests the need for caution in interpreting our results.

Some contradictory data exists on the frequency of inversions in wild populations of $D$. willistoni from RS. As stated by Cordeiro and Winge (1995), these populations: "were shown to be nearly devoid of inversions in the $\mathrm{X}$ chromosome, confirming that the southern, as well as the northern (Townsend, 1952) marginal regions are ecologically stringent for this species". However, no individuals completely devoid of inversions were observed in wild or urban samples from RS (Valente and Morales, 1985; Valente and Araújo, 1986b; Valente et al., 1993). Earlier reports of inversion frequencies made by $\mathrm{Da}$ Cunha and Dobzhansky (1954) supported the observations by Valente et al. (1993). The southernmost Brazilian state of Rio Grande do Sul (RS) and Uruguay are not separated by geographical barriers as rivers, mountains or deserts. The main difference between these regions is, apparently, climatic. The climate in Uruguay is more temperate whereas RS is in a transition zone between subtropical and temperate regions (Moreno, 1961). However, climate alone may be insufficient to explain the observed inversion differences. Other possibilities include those discussed below.

Studies of other $D$. willistoni populations subjected to different climates could help in understanding the present findings. Monthly samples of $D$. willistoni collected from September 1978 to May 1982 in two forest reserves (Parque do Turvo and Parque de Itapuã) located in regions of different climate, flora and fauna were studied by Valente and Araújo (1986b). According to these authors, temperature explained $90 \%$ of the variation in population size at Parque do Turvo, where the climate was more constant and warm. Intrinsic factors, such as the frequencies of inversions, accounted for the regulation of population dynamics at Itapuã wheter there was great meteorological instability. At both localities, the frequencies of inversions contributted to different extents, suggesting that biotic and abiotic variables may act differently in each population. Given these circumstances, stable climatic factors that regulate the cycle of plants on which the populations of flies depend, predominate in Turvo, whereas the unpredictability of the environment in Itapuã, makes chromosomal polymorphism a useful means of overcoming local hardships. These observations differences lead us to hypothesize that the success of $D$. willistoni in Uruguay may be attributed to the plasticity of its chromosomal polymorphism.

Data on the chromosomal polymorphism of $D$. paulistorum samples from Porto Alegre (Santos and Valente, 1990; Valiati and Valente, 1997) may provide other explanations. Examination of the urban "colonizer" populations of $D$. paulistorum over a period of 10 years (1985 to 1995 ) revealed a progressive occupation of this unusual environment (Valiati and Valente, 1996 and unpublished data). In parallel with the territory expansion, the urban populations of $D$. paulistorum showed an increase in inversion types, the occurrence of "new" inversions, and the loss of other previously detected inversions (Santos and Valente, 1990). This "urban colonization" suggested the existence of considerable genomic plasticity that flourished under favorable conditions.

As stressed by Da Cunha and Dobzhansky (1954), the absence of $D$. paulistorum, the closest sibling species to $D$. willistoni, could allow an expansion of chromosomal polymorphism in the latter. Pavan et al. (1957) used this hypothesis to explain the high chromosomal polymorphism in populations of $D$. willistoni, $D$ paulistorum and $D$. tropicalis, each of them dominant in samples from Caribbean islands. D. willistoni is the sole species of the willistoni sibling group in Uruguay, whereas in RS, it is sympatric with $D$. paulistorum. Whether this distribution accounts for the high polymorphism in chromosomal inversions found in populations from Uruguay remains to be determined. 
Finally, the mobilization of transposable elements (recognized by their ability to promote chromosomal rearrangements) under circumstances such as those during environmental stress, must also be considered. As reviewed by Fontdevila (1992), studies of colonizer Drosophila species, including D. buzzatii in South America and Europe, have suggested the mobilization of transposable elements to explain the high levels of chromosomal variability among the populations studied (Fontdevila et al., 1981, 1982). Another explanation, but not mutually exclusive from those above, was proposed by Carson and Wisotzkey (1989). Based on experimental populations of D. silvestris, these authors suggested that an increase in genetic variability resulted from stochastic events following a strong, heat induced bottleneck. The stochastic change in the chromosomal architecture caused by recombination appeared a few generations after the bottleneck and, as consequence, elevated the number of novel chromosomal variants. These variants subsequently suffered the action of natural selection. If we consider that the populations of $D$. willistoni in Uruguay are small and subject to stochastic events, they could provide a stronger source of genetic variability than larger central populations.

\section{Acknowledgements}

The authors thank Dr. María E. Martínez and Dr. Orfeo Crosa for help with field collections. This work was supported by the Comisión Sectorial de Investigaciones Científicas (CSIC) of the University de La Republica, Uruguay, and by the Brazilian agencies CNPq, FINEP, FAPERGS and PROPESQ-UFRGS.

\section{References}

Ashburner M (1967) Patterns of puffing activity in the salivary gland chromosomes of Drosophila. I. Autosomal puffing patterns in a laboratory stock of Drosophila melanogaster. Chromosoma 27:47-63.

Burla H, Da Cunha AB, Cavalcanti AGL, Dobzhansky T and Pavan C (1950) Population density and dispersal rates in Brazilian Drosophila willistoni. Ecology 31:393-404.

Carson HL and Wisotzkey RG (1989) Increase in genetic variance following a population bottleneck. Am Nat 134:668-673.

Cordeiro AR and Dobzhansky T (1954) Combining ability of certain chromosomes in Drosophila willistoni and invalidation of the "wild type" concept. Am Nat 88:75-86.

Cordeiro AR, Winge H (1995) Levels of evolutionary divergence of Drosophila willistoni sibling species. In: Levine L (ed) Genetics of Natural Populations. The Continuing Importance of Theodosius Dobzhansky. Columbia University Press, New York, pp 262-280.

Da Cunha AB, Burla H and Dobzhansky T (1950) Adaptive chromosomal polymorphism in Drosophila willistoni. Evolution 4:212-235.

Da Cunha AB and Dobzhansky T (1954) A further study of chromosomal polymorphism in Drosophila willistoni in its relation to the environment. Evolution 8:119-134.
Da Cunha AB, Dobzhansky T, Pavlovsky O and Spassky B (1959) Genetics of natural populations. XXVIII. Supplementary data on the chromosomal polymorphism in Drosophila willistoni in its relation to the environment. Evolution 13:389-404.

Dobzhansky T (1950) The chromosomes of Drosophila willistoni. J Hered 41:156-158.

Dobzhansky T (1957) Genetics of natural populations. XXVI. Chromosomal variability in island and continental populations of Drosophila willistoni from Central America and the West Indies. Evolution 11:280-293.

Dobzhansky T (1965) "Wild" and "domestic" species of Drosophila. In: Baker HG and Stebbins GL (eds) The Genetics of Colonizing Species. Academic Press, London, pp 533-551.

Dobzhansky T, Burla H and Da Cunha AB (1950) A comparative study of chromosomal polymorphism in sibling species of the willistoni group of Drosophila. Am Nat 84:229-245.

Dobzhansky T and Da Cunha AB (1955) Differentiation of nutritional preferences in Brazilian species of Drosophila. Ecology 36:34-39.

Dobzhansky T and Pavan C (1950) Local and seasonal variations in relative frequencies of species of Drosophila in Brazil. J Anim Ecol 19:1-14.

Ehrman L and Powell JR (1982) Drosophila willistoni species group. In: Ashburner M, Carson HL and Thompson JN Jr (eds) The Genetics and Biology of Drosophila. v 3b. Academic Press, London, pp 193-225.

Ephrussi B and Beadle GW (1936) A technique of transplantation for Drosophila melanogaster. Am Nat 70:218-225.

Everitt BS (1992) The Analysis of Contingency Tables. 2 ed. Chapman Hall, London.

Fontdevila A (1992) Genetic instability and rapid speciation: are they coupled? Genetica 86:247-258.

Fontdevila A, Ruiz A, Alonso G and Ocaña J (1981) The evolutionary history of Drosophila buzzatii. I. Natural chromosomal polymorphism in colonized populations of the old world. Evolution 35:148-157.

Fontdevila A, Ruiz A, Ocaña J and Alonso G (1982) Evolutionary history of Drosophila buzzatii. II. How much has chromosomal polymorphism changed in colonization? Evolution 36:843-851

Goñi B, Martínez ME and Daguer P (1997) Studies of two Drosophila (Diptera, Drosophilidae) communities from urban Montevideo, Uruguay. Revta Bras Ent 41:89-93.

Goñi B, Martínez ME, Valente VLS and Vilela CR (1998) Preliminary data on the Drosophila species (Diptera, Drosophilidae) from Uruguay. Revta Bras Ent 42:131-140.

Ludwig W (1950) Zur Theorie der konkurrenz. Die Annidation (Einnischung) als fünfter Evolutionsfaktor: Neve Ergeb Probleme Zool, Klatt Festschrift 1950:516-537.

Moreno jA (1961) Clima do Rio Grande do Sul. Bolm Geogr Porto Alegre, 6:49-83.

Parsons PA and Stanley SM (1981) Domesticated and widespread species. In: Ashburner M, Carson HL and Thompson JN Jr (eds) The Genetics and Biology of Drosophila. v. 3a. Academic Press, London, pp 349-393.

Pavan C, Dobzhansky T and Da Cunha AB (1957) Heterosis and the elimination of weak homozygotes in natural populations of three related species of Drosophila. Proc Natl Acad Sci USA 43:226-234. 
Regner LP, Pereira MSO, Alonso CEV, Abdelhay E and Valente VLS (1996) Genomic distribution of $P$ elements in Drosophila willistoni and a search for their relationship with chromosomal inversions. J Hered 87:191-198.

Regner LP and Valente VLS (1993) Drosophila willistoni mating activity - urbanization effects and a search for its chromosomal basis. Evol Biológica 7:327-349.

Roff DA and Bentzer P (1989) The statistical analysis of mitochondrial DNA polymorphisms: $\chi 2$ and the problem of small samples. Mol Biol Evol 6:539-545.

Saavedra CCR, Napp M, Reguly ML and Valente VLS (2001) Isoenzymatic polymorphisms in urban populations of Drosophila willistoni. Revta Chil Hist Nat 74:47-53.

Santos RA and Valente VLS (1990) On the occurrence of Drosophila paulistorum Bobzhansky \& Pavan (Diptera, Drosophilidae) in an urban environment: Ecological and cytological observations. Evol Biológica 4:253-268.

Sneath PH and Sokal RR (1973) Numerical Taxonomy. WH Freeman, San Francisco.

Soulé M (1973) The epistasis cycle: a theory of marginal populations. Ann Rev Ecol Syst 4:165-187.

Spassky B, Richmond RC, Pérez-Salas S, Pavlovsky O, Mourão CA, Hunter AS, Hoenigsberg H, Dobzhansky T and Ayala FJ (1971) Geography of the sibling species related to Drosophila willistoni and the semispecies of the Drosophila paulistorum complex. Evolution 25:129-143.

Townsend JI (1952) Genetics of marginal populations of Drosophila willistoni. Evolution 6:428-442.

Townsend JI (1958) Chromosomal polymorphism in Caribbean island populations of Drosophila willistoni. Proc Natl Acad Sci USA 44:38-42.

Valente VLS and Araújo AM (1986a) Comments on breeding sites of Drosophila willistoni Sturtevant (Diptera, Drosophilidae). Revta Bras Ent 30:281-286.
Valente VLS and Araújo AM (1986b) Chromosomal polymorphism, climatic factors and variation in population size of Drosophila willistoni in Southern Brazil. Heredity 57:149160.

Valente VLS and Morales NB (1985) New inversions and qualitative description of inversion heterozygotes in natural populations of Drosophila willistoni inhabiting two different regions in the State of Rio Grande do Sul, Brazil. Revta Bras Genet 8:167-173.

Valente VLS, Rohde C, Valiati VH, Morales NB and Goñi B (2001) Chromosome inversions occurring in Uruguayan populations of Drosophila willistoni. Drosophila Information Service 84:55-59.

Valente VLS, Ruszczyk A and dos Santos RA (1993) Chromosomal polymorphism in urban Drosophila willistoni. Revta Bras Genet 16:307-319.

Valiati VH and Valente VLS (1996) Observations on ecological parameters of urban populations of Drosophila paulistorum Dobzhansky \& Pavan (Diptera, Drosophilidae). Revta Bras Ent 40:567-581.

Valiati VH and Valente VLS (1997) Chromosomal polymorphism in urban populations of Drosophila paulistorum. Braz J Genet 20:567-581.

\section{Appendix 1}

Frequency (\%) of chromosome inversions, total heterozygosis, and mean number of inversions of the IIL (A), IIR (B) and III (C) chromosome arms of urban Drosophila willistoni. Percentages above 100 after summation indicate more than one inversion per chromosome arm (modified of Valente et al., 1993), with permission. $\mathrm{C}=$ chromosome; $\mathrm{I}=$ inversion. 